\title{
Harmonic aspects of wind power integration
}

\author{
Math H. J. BOLLEN (ه), Kai YANG
}

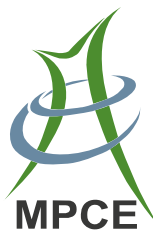

\begin{abstract}
This paper discusses a number of ways in which wind power installations can impact the harmonic levels in the power system. Wind turbines are an additional source of harmonic emission, especially when it concerns "non-characteristic harmonics." Parallel resonances can amplify the emission from individual turbines. A mathematical model is developed to quantify this amplification. Series resonances can result in high currents, driven by the background voltage distortion in the transmission grid, flowing into the wind park. Weakening of the transmission grid will increase lower order harmonics but reduce higher order harmonics.
\end{abstract}

Keywords Power quality, Power system harmonics, Wind power

\section{Introduction}

The increasing demand for sustainable energy is one of the driving forces behind the increasing use of wind power by means of wind turbines in electric power systems. The overall impact of wind power on the grid is discussed among others in [1] and [2]. Modern wind turbines commonly employ variable-speed generator technology associated with a powerelectronic converter as part of the grid connection. A drawback of the use of power electronics is the emission of harmonic currents. Consequently, a systematic study on the emission from wind power installations is needed, which holds for individual wind turbines as well for complete installations.

Received: 28 May 2012 / Accepted: 9 August 2012 / Published online: 5 July 2013

(C) The Author(s) 2013. This article is published with open access at Springerlink.com

M. H. J. BOLLEN, K. YANG, Electric Power Engineering, Luleå University of Technology, 93187 Skellefteå, Sweden

( $₫)$ e-mail: math.bollen@1tu.se

K. YANG

e-mail: kai.yang@1tu.se
Wind power installations impact the harmonic levels through their emission. In addition, they impact the resonance frequencies of the grid due to the presence of large amounts of capacitance in forms of underground cables and capacitor banks. These resonances cause an amplification of the emission from individual turbines into the public grid and a flow of harmonic currents from the public grid into the wind park. Different resonances and the way in which they impact the harmonic currents at the interface between a wind park and the grid are discussed as well.

The replacement of conventional power stations by wind power installations has an indirect impact on harmonic levels. Wind power installations contribute less to the short-circuit capacity of the transmission system than conventional power stations. As a result, the transmission system becomes weaker, thus resulting in an increase in harmonic voltage levels.

\section{Emission from individual turbines}

The emission from individual wind turbines has been studied [3-17]. Generally, it can be concluded that the emission from individual turbines is relatively small. Some authors point to a relatively high emission at higher harmonic orders and for other frequencies where the distortion levels are traditionally lower.

\subsection{Power-electronic converters}

Most of the modern wind turbines installed in the grid contain a power-electronic converter which can either be part of a full-power converter or a doubly-fed induction generator (DFIG). Measurements of the emission from such two turbines, both of $2 \mathrm{MW}$ nominal power, are shown in Figs. 1 and 2 [9]. Other measurements in [9] show that the differences between the two spectra are not 


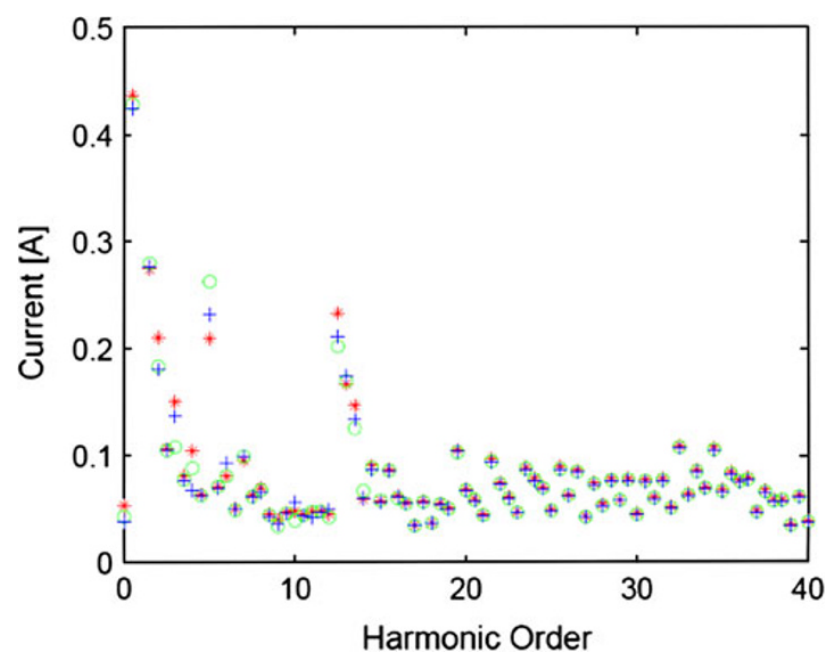

Fig. $195 \%$ values of the harmonic and interharmonics subgroups in the current from a Nordex N90 turbine, measured at $22 \mathrm{kV}$

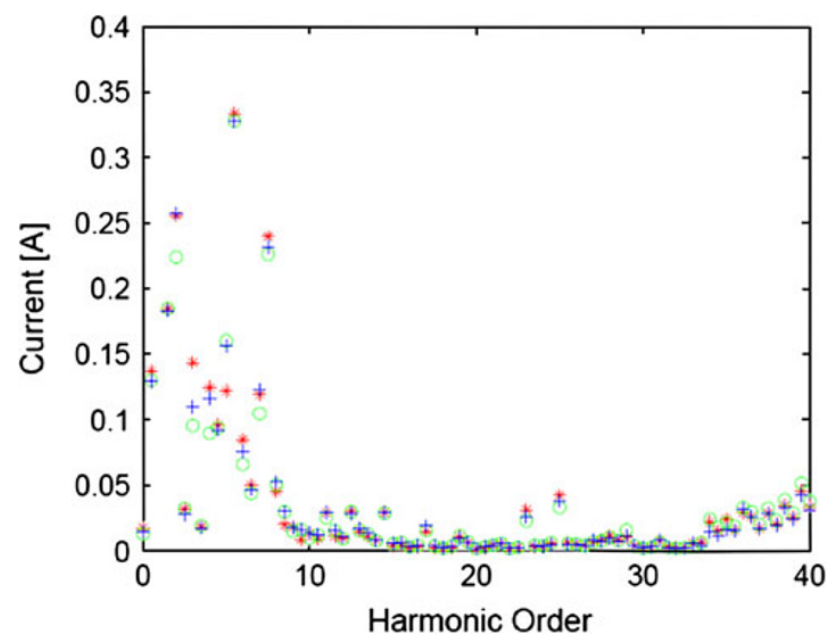

Fig. $295 \%$ values of the harmonic and interharmonics subgroups in the current from a Vestas V90 turbine, measured at $32 \mathrm{kV}$

due to general differences between full-power converters and DFIG. The currents were in both cases measured on the grid-side of the turbine transformer (i.e., at the connection point from the turbine to the medium-voltage collection grid), during a period of several weeks. The harmonic and interharmonics (IHs) subgroups (as defined in IEC 61000-4-7) were obtained over each 10-min interval, and $95 \%$ value for each subgroup is shown in Figs. 1 and 2.

The spectrum of the Nordex N90 turbine shows a broadband character with a narrowband emission around harmonic 13 and for the fifth harmonic. Besides, at lower frequencies (up to harmonic 2), the emission is relatively high. This is probably due to strong variations in active power flow (fundamental current) but not caused by the power electronics.
The spectrum of the Vestas V90 does not show the broadband component over the whole frequency range. Instead, it shows some components at lower frequencies and an increase in emission toward zero frequency and the upper limit of the frequency band shown. The former is probably due to fast changes in the production and the latter caused by the switching frequency.

For the interpretation of the severity of the emission, the nominal currents should be known, which are $66 \mathrm{~A}$ for the Nordex N90 turbine and 36 A for the Vestas V90 turbine. The vertical scale corresponds to $0.7 \%$ of nominal current in Fig. 1 and to $1.1 \%$ in Fig. 2. The relative levels of the 5 dominating harmonic $(\mathrm{H})$ and $\mathrm{IHs}$ subgroups are shown in Table 1 . The only common component with most other sources of harmonic distortion is the fifth harmonic. The emission levels are lower even for the dominating components, when comparing with the emission from an induction machine, as shown in Table 2.

An alternative look on the emission from the two wind turbines is shown in Fig. 3. In this case, the basic measurements, obtained every 10 min during several weeks, were $200 \mathrm{~ms}$ windows of data, at $12.8 \mathrm{kHz}$ sampling rate. The spectrum was obtained by taking a DFT over the $200 \mathrm{~ms}$ window. The average of the magnitude spectra over this whole period is shown in Fig. 3. The frequency scale is split

Table 1 Highest harmonic or interharmonics subgroups in the emission from two modern wind turbines

\begin{tabular}{lllll}
\hline Nordex N90 & & & \multicolumn{2}{l}{ Vestas V90 } \\
\cline { 1 - 2 } Order & Percentage & & Order & Percentage \\
\hline IH 0.5 & 0.66 & IH 1.5 & 0.51 \\
IH 1.5 & 0.42 & H 2 & 0.72 \\
H 2 & 0.32 & H 5 & 0.45 \\
H 5 & 0.49 & IH 5.5 & 0.93 \\
IH 12.5 & 0.35 & IH 7.5 & 0.67 \\
\hline
\end{tabular}

Table 2 Typical distortion from a wound-rotor induction machine

\begin{tabular}{|c|c|c|}
\hline $\begin{array}{l}\text { Frequency } \\
(\mathrm{Hz})\end{array}$ & $\begin{array}{l}\text { Current (\% of } \\
\text { fundamental) }\end{array}$ & Cause \\
\hline 20 & 3.0 & Pole unbalance \\
\hline 40 & 2.4 & Rotor-phase unbalance \\
\hline 50 & 100 & Fundamental \\
\hline 80 & 2.3 & Pole unbalance \\
\hline 220 & 2.9 & Fifth and seventh harmonics \\
\hline 320 & 3.0 & Fifth and seventh harmonics \\
\hline 490 & 0.3 & $\begin{array}{l}\text { Eleventh and thirteenth } \\
\text { harmonics }\end{array}$ \\
\hline 590 & 0.4 & $\begin{array}{l}\text { Eleventh and thirteenth } \\
\text { harmonics }\end{array}$ \\
\hline
\end{tabular}



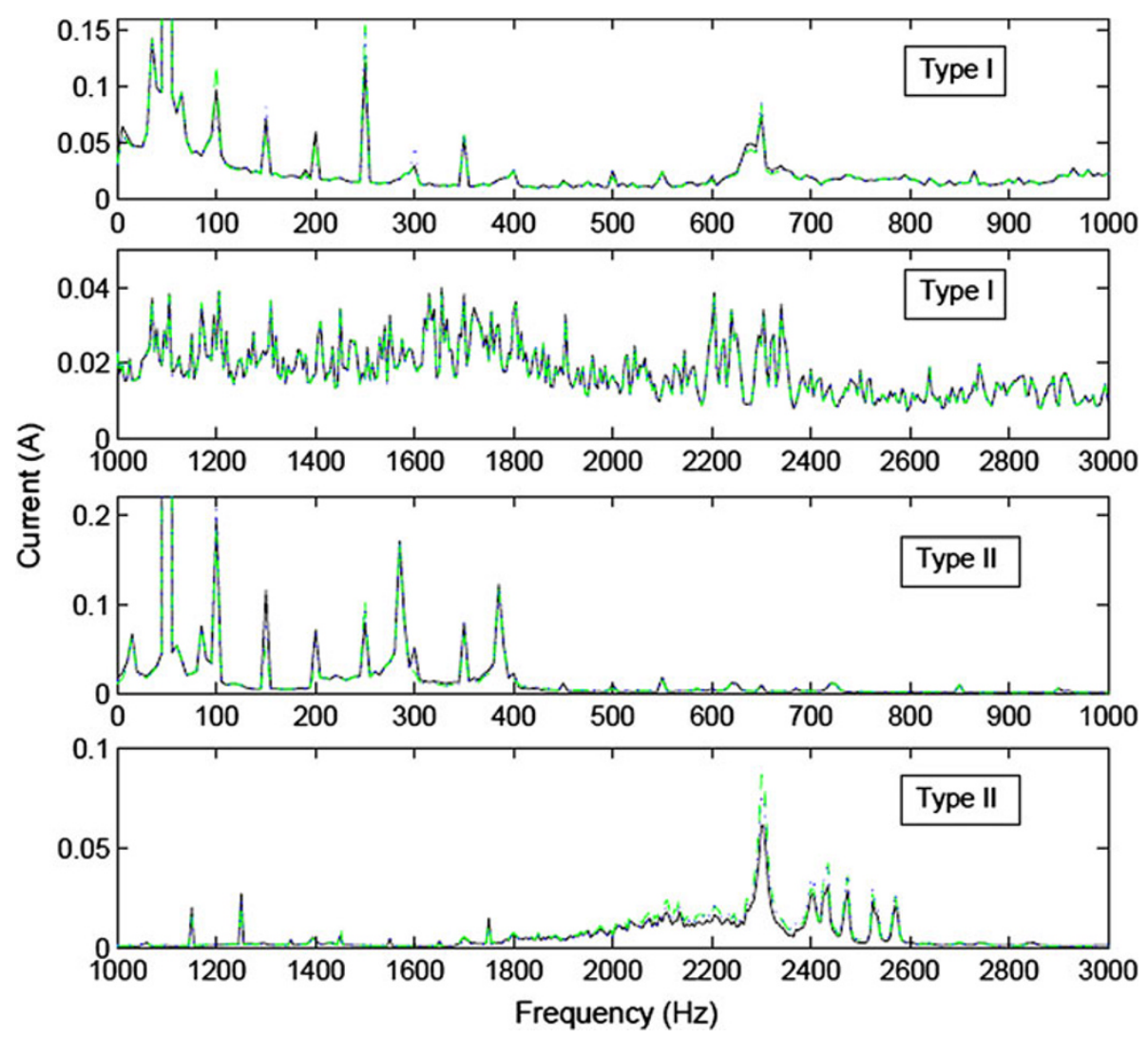

Fig. 3 Average spectrum from Nordex N90 turbine (Type I) and Vestas V90 (Type II)

in two parts: up to $1 \mathrm{kHz}$ and from 1 to $3 \mathrm{kHz}$. The difference in vertical scale among the 4 plots should be noticed before making a comparison of the emission levels.

There are a number of narrowband components in the low-frequency part of the frequency scale, mainly at the harmonic frequencies (2, 3, 4, and 5) and also at IH frequencies. The broadband component throughout the frequency band for turbine I and the increase toward low frequencies for both turbines are visible.

The Nordex N90 turbine shows an emission peak around $650 \mathrm{~Hz}$ and the Vestas V90 turbine around 2,300 Hz. The switching frequency of the power electronics in the converter is the most likely explanation.

The broadband emission for the Nordex N90 turbine is also visible and up to $3 \mathrm{kHz}$.

\subsection{Induction machines}

Electrical machines, directly connected to the grid, are normally not a source of harmonic distortion. When comparing to the heavy distorted currents from computer televisions, etc., the current waveform from an electrical machine is close to sinusoidal. Still, the emission cannot be neglected in all cases. A typical emission spectrum of an induction machine in [18] is reproduced in Table 2. Currents up to several percent of the fundamental, at lower IHs frequencies, can be expected from induction machines. These levels are higher than the emission from modern turbines with power electronics converter.

\subsection{Power transformers}

The low levels of emission from individual turbines show that the contribution made by power transformers to the emission can no longer be neglected.

The harmonic emission due to the magnetizing current is below $1 \%$ of the rated current of the transformer [19]. However, at high levels of the rms voltage, the resulting saturation of the transformer core will cause much higher emission levels. Based on Fig. 3.3 in [18], the magnetizing harmonics are estimated for $110 \%$ and $120 \%$ of nominal voltage as shown in Table 3.

The values are relatively low, even for $120 \%$ of the nominal voltage, but they are bigger than the emission from the wind turbines at these frequencies. Furthermore, the magnetizing harmonics are limited to the lower order odd harmonics.

\section{Emission from wind parks}

When studying the harmonic emission of a wind farm, two separate issues should be considered: the harmonic 
Table 3 Magnetizing harmonics of a transformer, as a percentage of the rated current, for two values of the terminal voltage

\begin{tabular}{llll}
\hline & Harm 3 & Harm 5 & Harm 7 \\
\hline $110 \%$ Unom & 1.5 & 1.1 & 0.7 \\
$120 \%$ Unom & 5.3 & 3.7 & 2.1 \\
\hline
\end{tabular}

emissions from individual wind turbines and the propagation from the individual wind turbines through the collection grid to the public grid. The harmonic emission from an individual wind turbine is discussed in the previous section. The impact of the wind farm on the propagation has not been studied, but harmonic resonances have been widely studied $[1,3,20-23]$. The parallel resonance has the main impact on the emission of the farm, thus the emission into the grid is several times higher than that of the individual turbines.

\subsection{Overall transfer function}

The role of the wind farm layout in this amplification has been studied in [4] and [24]. A mathematical model has been developed to quantify the propagation from all the turbines to the public grid. The model is based on the transfer function known from system and control theory.

The individual transfer function is a complex function of frequency that relates the (complex) current injected by the wind park into the public grid with the (complex) current injected by one individual turbine into the collection grid. As different turbines have different locations in the collection grid, their individual transfer functions are different.

A single function describing the collection grid as a whole is obtained by making a number of assumptions.

(1) The collection grid is a linear time-invariant system;

(2) The emissions from all turbines are, at all times and for all frequencies, identical in magnitude and random in phase angle;

(3) The presence of emission from other turbines does not impact the emission from a turbine.

Under these assumptions, an "overall transfer function" has been defined. It is a real function of frequency, and gives the ratio between the (magnitude of the) emission from the wind park into the public grid and the (magnitude of the) emission from one turbine into the collection grid. The amplitude of the overall transfer function $H_{\mathrm{g}}(\omega)$ is obtained from the amplitude of the individual transfer functions $H_{\mathrm{tg}}(\omega)$ by using the following expression:

$H_{\mathrm{g}}(\omega)=\sqrt{\sum_{t=1}^{N} H_{\mathrm{tg}}^{2}(\omega)}$.

\subsection{Three-turbine park}

Individual transfer functions and overall transfer function for a three-turbine wind park are presented in Fig. 4. The upper plots show the three individual transfer functions versus frequency. The maximum of the individual transfer function (due to parallel resonance) occurs between 5 and $10 \mathrm{kHz}$. The contribution of one turbine to the total emission of the wind park, at the resonance frequency, is about 40 times the emission from the turbine into the collection grid. When high emission from individual turbines occurs between 5 and $10 \mathrm{kHz}$ (for instance due to the switching frequency), high emission into the public grid can occur.

The lower plots, presenting overall transfer functions, show that the maxima are between 5 and $10 \mathrm{kHz}$. Since the maxima in the individual transfer functions occur at different frequencies, the maximum of the overall transfer function is also about 40. No additional amplification occurs due to the combined emission from the individual turbines. The emission into the public grid is at most 45 times the emission from one turbine, or 15 times the emission from the three turbines.

Additional resonance frequencies occur around 50 and $150 \mathrm{kHz}$. The amplification is low at those frequencies. A general conclusion from the studies is that the overall transfer function becomes negligible at frequencies above the first resonance frequency.

The calculations have been repeated for low increase of resistance with frequency (low damping) and for different sizes of capacitor bank presenting in the collection grid. The results are summarized in Table 4 . The increase of the cable and the transformer resistance with the frequency greatly influences the maximum overall transfer. Besides, once a capacitor bank is present, it dominates the transfer function.

\subsection{Ten- and hundred-turbine parks}

The results of a 10-turbine and a 100-turbine wind park are summarized in Tables 5 and 6. Larger parks contain more cables and more capacitance even without a capacitor bank. The result is a lower resonance frequency for the case without a capacitor bank.

\subsection{Calculation of the total emission}

The total emission from the wind park is obtained by multiplying the overall transfer function, as defined in Sect. 3.1, with the emission from an individual turbine, some examples are shown in Sect. 2.1.

As an illustrative example, a $200 \mathrm{MW}$ park consists of 100 turbines with $2 \mathrm{MW}$ rated power each. No capacitor 

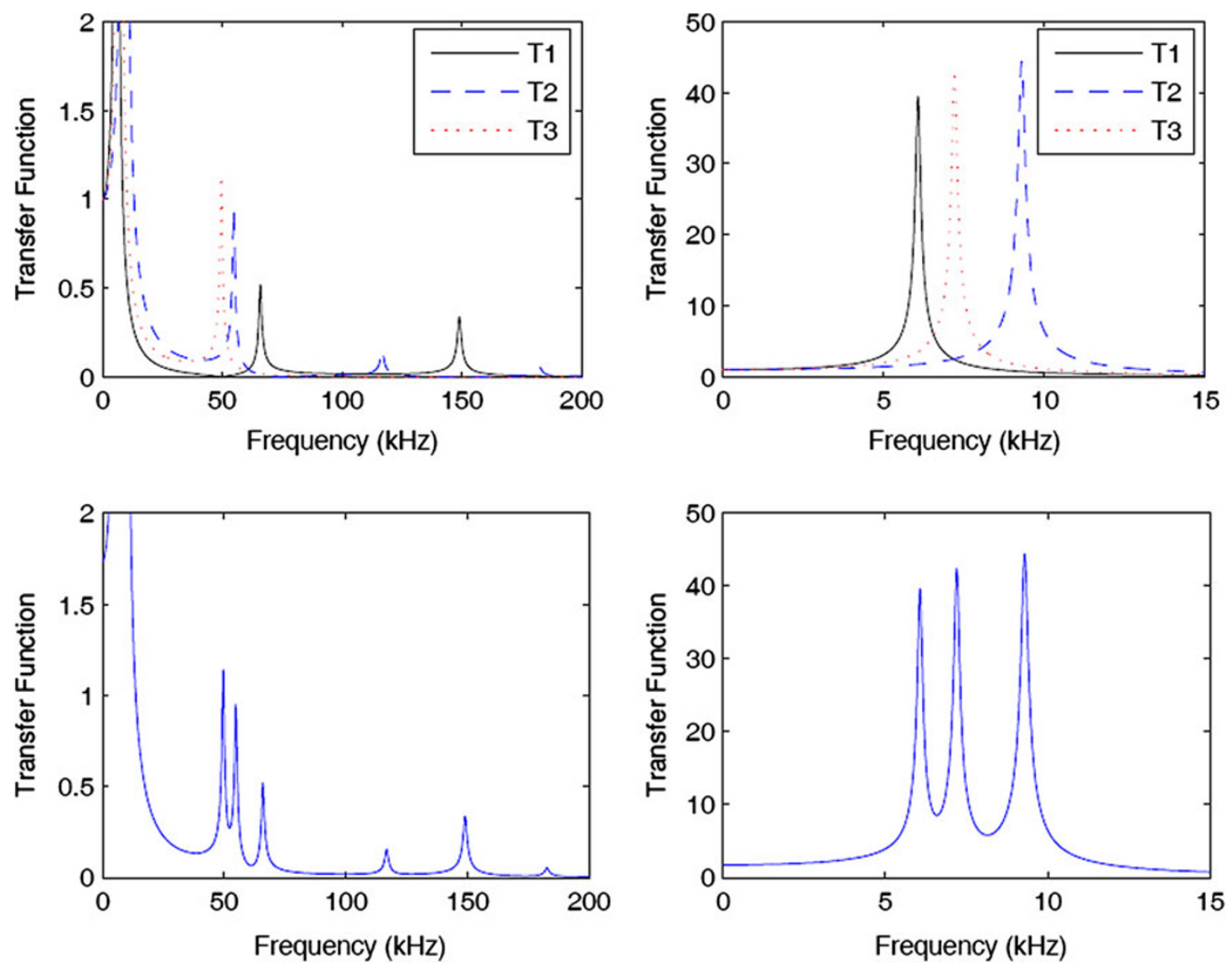

Fig. 4 Individual transfer functions (top) and overall transfer function (bottom) for a three-turbine wind park; 0-200 kHz (left) and 0-15 kHz (right)

bank is present in the collection grid; therefore, the first row of Table 6 should be used. Assuming that the emission from one turbine, at the resonance frequency of $1,850 \mathrm{~Hz}$, is $0.5 \%$ of the rated current of the turbine.

For low damping (a worst-case situation), the amplification at the resonance frequency is 371 times, thus the emission from the park into the public grid equals (371 times $0.5 \%$ ) about $190 \%$ of the rated current of one turbine or $1.9 \%$ of the rated current of the park.

\section{Harmonic resonances}

A harmonic resonance occurs when the impedance of a circuit containing capacitors and inductors has a maximum or a minimum. Such resonances can amplify harmonic currents and voltages in the grid, and they should be seriously considered when high harmonic levels are to be prevented.

Two different types of harmonic resonances should be distinguished: parallel resonances and series resonances $[18,23,25]$. For a parallel resonance, the impedance of the circuit is high. A moderate harmonic current from a source of harmonic distortion can result in a high harmonic voltage. A parallel resonance at the same time can result in an amplification of the harmonic current, thus the current elsewhere in the grid could be higher than that close to the source of the distortion.

For a series resonance, the impedance of the circuit is low. In that case, a moderate harmonic voltage distortion can result in a high harmonic current. A series resonance can also result in an amplification of the harmonic voltage.

To explain the impacts of these two types of resonance on the emission from a wind park, a distinction should be made between the primary emission and the secondary emission [26]. These terms describe the interaction between different sources (fluorescent lamps) of high-frequency emission in a low-voltage installation. The primary emission is the current at the equipment terminals due to the power-electronic switching in the device, and the secondary emission is the current due to power-electronic switching in neighboring devices.

The concept can easily be extended to individual wind turbines and wind parks at lower frequencies. At the connection point between the wind park and the public grid, the two types of emission are defined as follows. 
Table 4 Dominant resonance frequency and maximum of the overall transfer function for a 3-turbine wind park

\begin{tabular}{|c|c|c|c|}
\hline \multirow{2}{*}{$\begin{array}{l}\text { Capacitor } \\
\text { bank }\end{array}$} & \multirow{2}{*}{$\begin{array}{l}\text { Resonance frequency } \\
(\mathrm{Hz})\end{array}$} & \multicolumn{2}{|c|}{ Maximum overall transfer } \\
\hline & & $\begin{array}{l}\text { High } \\
\text { damping }\end{array}$ & $\begin{array}{l}\text { Low } \\
\text { damping }\end{array}$ \\
\hline None & 6,050 & 15.6 & 39.6 \\
\hline 500 kvar & 980 & 26.5 & 47.5 \\
\hline 1,000 kvar & 690 & 26.6 & 44.8 \\
\hline
\end{tabular}

Table 5 Dominant resonance frequency and maximum of the overall transfer function for a 10-turbine wind park

\begin{tabular}{llll}
\hline $\begin{array}{l}\text { Capacitor } \\
\text { bank }\end{array}$ & $\begin{array}{l}\text { Resonance frequency } \\
(\mathrm{Hz})\end{array}$ & \multicolumn{2}{l}{ Maximum overall transfer } \\
\cline { 3 - 4 } & & $\begin{array}{l}\text { High } \\
\text { damping }\end{array}$ & $\begin{array}{l}\text { Low } \\
\text { damping }\end{array}$ \\
\hline None & 1,850 & 33.6 & 55.6 \\
2.5 Mvar & 750 & 50.6 & 82.3 \\
5 Mvar & 550 & 51.3 & 81.0 \\
\hline
\end{tabular}

Table 6 Dominant resonance frequency and maximum of the overall transfer function for a 100-turbine wind park

\begin{tabular}{|c|c|c|c|}
\hline \multirow{2}{*}{$\begin{array}{l}\text { Capacitor } \\
\text { bank }\end{array}$} & \multirow{2}{*}{$\begin{array}{l}\text { Resonance frequency } \\
(\mathrm{Hz})\end{array}$} & \multicolumn{2}{|c|}{ Maximum overall transfer } \\
\hline & & $\begin{array}{l}\text { High } \\
\text { damping }\end{array}$ & $\begin{array}{l}\text { Low } \\
\text { damping }\end{array}$ \\
\hline None & 1,560 & 204 & 371 \\
\hline 25 Mvar & 710 & 236 & 388 \\
\hline 50 Mvar & 530 & 234 & 363 \\
\hline
\end{tabular}

(1) The primary emission is the part of the current at the point of connection between the wind park and the public grid caused by the harmonic emission of the individual turbine;

(2) The secondary emission is the part of the current caused by sources of emission outside of the park.

The primary emission of the wind park is impacted by the emission from individual turbines and the overall transfer function. Parallel resonances can amplify the primary emission. High levels of primary emission into the public grid can be expected at parallel resonances that occur at frequencies for which the emission from individual turbines is non-negligible.

The emission from individual turbines with powerelectronic converters can be non-negligible for any frequency (harmonic and $\mathrm{IH}$ ) up to a few $\mathrm{kHz}$. Any parallel resonance frequency up to a few $\mathrm{kHz}$ can thus be a cause for concern. In addition, no significant transfer occurs above the first resonance frequency (the one shown in Table 4 through Table 6), which means that for all but the smallest parks, primary emission above 1 or $2 \mathrm{kHz}$ is not a concern.

The secondary emission is the one driven by the background voltage distortion in the public grid. Due to series resonances, the background voltage can cause high currents flowing into the collection grid and high voltage distortion in the collection grid. High levels of secondary emission can be expected when a series resonance takes place at a frequency where the background voltage distortion is nonnegligible. This is in practice only at the characteristic harmonics $(5,7,11,13,17,19$, etc.).

The current measured at the point of connection of a wind park to the public grid is a combination of the primary emission and the secondary emission. When the emission is unexpectedly high, both series and parallel resonances should be considered.

\section{Replacement of conventional production}

The replacement of large conventional power stations connected to the transmission grid by wind parks makes the transmission grid weaker. At the power system frequency, weakening of the grid implies an increase of the source impedance, which is not the case at harmonic frequencies illustrated in Fig. 5. The source impedance has been calculated for a $132 \mathrm{kV}$ network with a 30 Mvar capacitor bank connected and damping provided by 100 MW resistive load. Two values of the fault level have been assumed: 1,000 MVA (as the weak grid in Fig. 5) and 3,000 MVA (as the strong grid in Fig. 5). The reduction in fault level results in a shift in resonance frequency to a lower value (from harmonic 10 to harmonic 6). For low frequencies, the source impedance increases and the same amount of emission will result in higher voltage distortion. While for high frequencies, the source impedance gets smaller thus results in lower voltage distortion. This assumes that the emission remains the same.

The situation is not as severe as it may look. Because of the variation in consumption through the year, the number of generators connected to the transmission shows a variation even without the presence of wind power. Also outages due to failure or maintenance result in variation in the number of generators connected to the transmission grid. The local reduction in fault level also results in an increase in harmonic voltage distortion at lower frequencies.

A high penetration of wind power could result in operational states where the voltage distortion close to large industrial installations becomes too high during a too high part of the year. There are a number of ways to address this. 


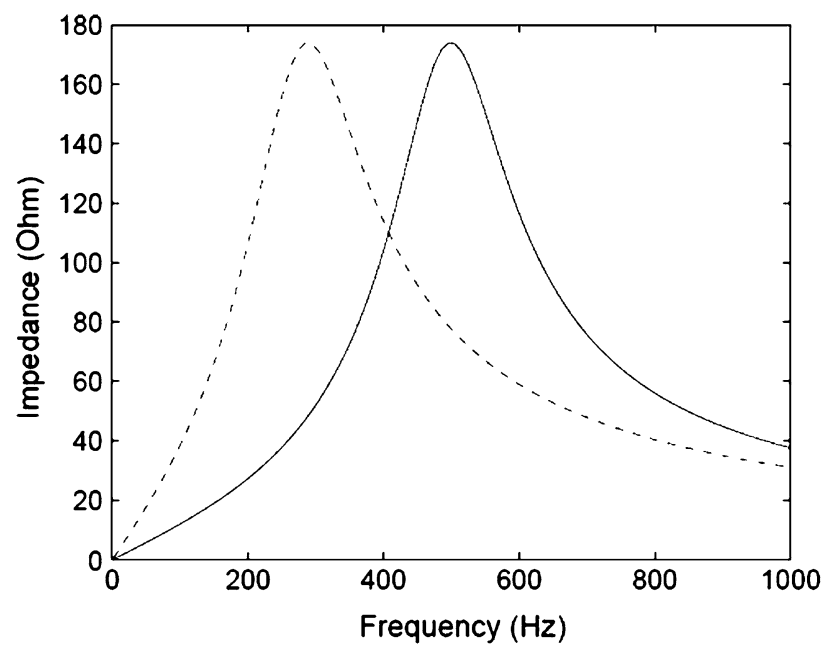

Fig. 5 Source impedance as a function of frequency for a strong grid (solid line) and a weak grid (dashed line)

(1) Higher levels of harmonic voltage distortion may be accepted during certain parts of the year. Its impact on the end-customer is likely to be limited because only a part of the voltage distortion originates from higher voltage levels. Capacitor banks at transmission level may, however, age faster. The overall higher voltage distortion could result in increasing aging for motor loads.

(2) Existing capacitor banks could be equipped with harmonic filters or additional harmonic filters, which brings additional costs for the transmission system operator.

(3) Emission limits for industrial installations remain to be set in terms of voltage distortion as is common practice for several network operators. This would result in additional costs for industrial installations.

\section{Conclusions}

Wind power installations impact the harmonic current and voltage distortion in the grid in several ways.

(1) Individual turbines are an additional source of harmonic emission. Measurements on turbines and comparison with other sources show that the emission of the characteristic harmonics is small. However, the emission of IHs and other non-characteristic harmonics is relatively high.

(2) Due to the capacitance in the collection grid, amplification of the emission from individual turbines occurs. It is quantified by a mathematical model developed in this paper. After applying the model to a number of turbines, a large amplification occurs around the first parallel resonance frequency between a few hundred $\mathrm{Hz}$ and a few $\mathrm{kHz}$ depending on the size of the park and the presence of any capacitor banks. Above the first resonance frequency, the emission from the park becomes negligible.

(3) Series resonances result in high harmonic currents flowing into the wind park, driven by the background voltage distortion in the transmission grid.

The replacement of conventional power stations with wind power results in a reduction of the short-circuit capacity of the transmission grid. The consequences are: a reduction of harmonic resonance frequencies, an increase of the voltage distortion below the resonance frequency, and a decrease of the voltage distortion above the resonance frequency.

Acknowledgments This study was supported by the VindForsk program, through Elforsk $\mathrm{AB}$, by Alstom Grid, and by Skellefteå Kraft Elnät AB.

Open Access This article is distributed under the terms of the Creative Commons Attribution License which permits any use, distribution, and reproduction in any medium, provided the original author(s) and the source are credited.

\section{References}

[1] Bollen MHJ, Hassan F (2011) Integration of distributed generation in the power system. Wiley-IEEE Press, Hoboken

[2] Fox B, Flynn D, Bryans L et al (2007) Wind power integration: connection and system operational aspects. Ins Eng Technol, London

[3] Bollen MHJ, Yao LZ, Rönnberg SK et al (2010) Harmonic and interharmonic distortion due to a windpark. In: Proceedings of the 2010 IEEE Power and Energy Society general meeting (PES'10), Minneapolis, 25-29 July 2010, p 6

[4] Yang K (2012) Wind-turbine harmonic emissions and propagation through a wind farm. Licentiate Thesis, Luleå University of Technology, Luleå

[5] Tentzerakis ST, Papathanassiou SA (2007) An investigation of the harmonic emissions of wind turbines. IEEE Trans Energy Conver 22(1):150-158

[6] Tentzerakis S, Paraskevopoulou N, Papathanassiou S et al (2008) Measurement of wind farm harmonic emissions. In: Proceedings of the IEEE power electronics specialists conference (PESC'08), Rhodes, 15-19 June 2008, pp 1769-1775

[7] Larsson $\AA$ (1997) Grid interaction and power quality of wind turbine generator systems. PhD Thesis, Chalmers University of Technology, Göteborg

[8] Yang K, Bollen MHJ, Wahlberg M (2011) Characteristic and non-characteristic harmonics from windparks. In: Proceedings of the CIRED 21st international conference electricity distribution (CIRED'11), Frankfurt, June 2011 pp 6-9

[9] Yang K, Bollen MHJ, Wahlberg M (2011) A comparison study of harmonic emission measurements in four windparks. In: Proceedings of the IEEE Power and Energy Society general meeting (PES'11), Detroit, 24-29 July 2011, p 7 
[10] Yang K, Bollen MHJ, Wahlberg M (2012) Comparison of harmonic emissions at two nodes in a windpark. In: Proceedings of the 15th IEEE international conference on harmonics and quality of power (ICHQP'12), Hong Kong, 17-20 June 2012, pp 313-319

[11] de Bronzeado HS, Rosas PAC, Feitosa EAN et al (1998) Behavior of wind turbines under Brazilian wind conditions and their interaction with the grid. In: Proceedings of the international conference on harmonics and quality of power (ICHQP'98), vol 2, Athens, 14-16 Oct 1998, pp 906-910

[12] Emanuel H, Schellschmidt M, Wachte LS et al (2009) Power quality measurements of wind energy converters with full-scale converter according to IEC 61400-21. In: Proceedings of the 10 th international conference on electrical power quality and utilisation (EPQU'09), Lodz, 15-17 Sept 2009, p 7

[13] Esposito G, Zaninelli D, Lazaroiu GC et al (2007) Impact of embedded generation on the voltage quality of distribution networks. In: Proceedings of the 9th international conference on electrical power quality and utilisation (EPQU'07), Barcelona, 9-11 Oct 2007, p 6

[14] Ladakakos PD, Ioannides MG, Koulouvari MI (1998) Assessment of wind turbines impact on the power quality of autonomous weak grids. In: Proceedings of the international conference on harmonics and quality of power (ICHQP'98), vol 2, Athens, 14-16 Oct 1998, pp 900-905

[15] Lindholm M, Rasmussen TW (2003) Harmonic analysis of doubly fed induction generators. In: Proceedings of the 5th international conference on power electronics and drive systems (PEDS'03), vol 2, Singapore, 17-20 Nov 2003, pp 837-841

[16] Liu KH, Wang L (2007) Analysis of measured harmonic currents and voltages contributed by a commercial wind power system. In: Proceedings of the 2007 IEEE power engineering society general meeting, Tampa, 24-28 June 2007, pp 6

[17] Tande JOG (1998) Impact of wind turbines on voltage quality. In: Proceedings of the international conference on harmonics and quality of power (ICHQP'98), vol 2, Athens, 14-16 Oct 1998, pp 1158-1161

[18] Arrillaga J, Watson NR (2003) Power system harmonics, 2nd edn. Wiley, Chichester

[19] ABB, Transformer handbook (2007)

[20] BalcellS J, Gonzalez D (1998) Harmonics due to resonance in a wind power plant. In: Proceedings of the 8th international conference on harmonics and quality of power (ICHQP'98), vol 2, Athens, Greece, 14-16 Oct 1998, pp 896-899

[21] Li J, Samaan N, Williams S (2008) Modeling of large wind farm systems for dynamic and harmonics analysis. In: Proceedings of the IEEE/PES transmission and distribution conference and exposition, Chicago, 21-24 Apr 2008, p 7

[22] Schostan S, Dettmann KD, Schulz D et al (2007) Investigation of an atypical sixth harmonic current level of a $5 \mathrm{MW}$ wind turbine configuration. In: Proceedings of the international conference on "Computer as a Tool" (EUROCON'07), Warsaw, 9-12 Sept 2007, pp 2529-2535

[23] Zheng R, Bollen MHJ, Zhong J (2010) Harmonic resonances due to a grid-connected wind farm. In: Proceedings of the 14th international conference on harmonics and quality of power (ICHQP'10), Bergamo, 26-29 Sept 2010, p 7

[24] Yang K, Bollen MHJ, Yao LZ (2011) Theoretical emission of study of windpark grids: Emission propagation between windpark and grid. In: Proceedings of the 11th international conference on electrical power quality and utilisation (EPQU'11), Lisbon, 17-19 Oct 2011, p 6

[25] Bollen MHJ, Gu IYH (2006) Signal processing of power-quality disturbance. Wiley-IEEE Press, Hoboken

[26] Rönnberg S, larsson A, Bollen M et al (2011) A simple model for interaction between equipment at a frequency of some tens of kHz. In: Proceedings of the CIRED 21st international conference electricity distribution (CIRED'11), Frankfurt, 6-9 June 2011

\section{Author Biographies}

Math H. J. BOLLEN (M'93-SM'96-F'05) received the M.Sc. and $\mathrm{Ph} . \mathrm{D}$. degrees from Eindhoven University of Technology, Eindhoven, The Netherlands, in 1985 and 1989, respectively. Currently, he is professor in electric power engineering at Luleå University of Technology, Skellefteå Sweden, and R\&D manager power systems at STRI AB, Gothenburg, Sweden. He has among others been a lecturer at the University of Manchester Institute of Science and Technology (UMIST), Manchester, U.K. (1993-1996), professor in electric power systems at Chalmers University of Technology, Gothenburg, Sweden (1996-2003) and technical expert at the Energy Markets Inspectorate, Eskilstuna, Sweden (2010-2012).

Kai YANG received his M.Sc. degree from Blekinge Institute of Technology, Sweden in 2009 and the Licentiate degree from Luleå University of Technology, Sweden in 2012. Now he is a Ph.D. student in the Electric Power Engineering Group at Luleå University of Technology, Skellefteå, Sweden. The main research interest is in the field of wind power quality, harmonics and distortion. 